\title{
Analysis and Design of Automated Transport and Path Planning for Robots in Cluttered Environments using Novel Hybrid Average Genetic-Neural Control Technique
}

\author{
Parhi Dayal $\mathbf{R}^{1 *}$ and Sat Chidananda ${ }^{2}$ \\ ${ }^{1}$ Department of Mechanical Engineering, National Institute of Technology Rourkela, Sundargarh, Odisha, India \\ ${ }^{2}$ Delhi Public School, Rourkela, Sundargarh, Odisha, India
}

Submission: March 08, 2021; Published: March 25, 2021

*Corresponding author: Parhi Dayal R, Department of Mechanical Engineering, National Institute of Technology Rourkela, Sundargarh, Odisha, India

\begin{abstract}
In the current investigation on automated transport and navigational path planning of robots, a new Hybrid Average Genetic-Neural (HAGN) technique has been developed. The HAGN technique uses genetic algorithm and multi layered neural technique as important parts for its development. The robots are equipped with several sensors to map the surrounding environments and to recognize the obstacles and targets around. During the navigation robots take into account front, left and right obstacle distances obtained from sensors to negotiate with obstacles and reach targets with the help of HAGN technique. To prove authenticity of the proposed method several simulation and experimental exercises have been carried out. Comparisons between simulation and experimental results are presented in pictorial and tabular forms. The deviation between simulation and experimental results are found to be within 2.8\%. Other engineering applications can also be addressed using HAGN AI technique.
\end{abstract}

Keywords: Genetic; Neural; Average; Robots; Artificial intelligence Navigation, Control

\section{Introduction}

Scientists and engineers have used different type of artificial intelligence techniques for addressing various engineering optimisation problems including various robots control related problems. Cuckoo birds laying eggs patterns have been mathematically modelled as cuckoo search algorithm [1-2] by researchers for solving control strategies of robots. Artificial potential field methods [3-4] have been used by researchers for automotive control of robots. Particle swarm optimisation method [5-7] is a community driven method used by engineers for addressing robot navigation problems. Artificial immune system [8-10] is one of the potential AI methods for addressing various engineering optimisation problems. Robots navigations have been addressed using artificial immune system in papers [11-13]. Firefly nature inspired algorithm [14,15] has been discussed by scientists and engineers for solving various optimisation problems. Paper [16] discusses navigation control of robots in unknown environments. Swarm intelligence technique [17-21] is inspired from pattern of herd community travel and has been used by researchers to solve optimisation problems including robots path optimisation problems. In today's world Artificial Intelligence [22-24] techniques play important roles in solving various complicated problems. Papers [25-27] discuss about robot navigation control using AI techniques. Path planning of mobile robots have been analysed and discussed in research papers [28-29].

Regression based analysis [30-32] is used by many engineers to address various optimisation problem. In ant colony method [33], behaviour of ant movement has been mathematically modelled by researchers to solve various optimisation problems in engineering fields. Papers [34-36] have discussed path planning of mobile robot using ant colony optimisation technique. Dayani AI technique [37] has been used by researchers to control robots in 
unknown environments. Crack identifications in various elements used for robotic structures have been done by the help of artificial intelligence techniques and are discussed in papers [38-45]. Genetic algorithm [46-47] is one of frontier biological inspired technique for solving various engineering problems. Papers [4850] discuss path planning of mobile robot using genetic algorithm.

Using various AI soft computing techniques researchers have tried to analyse vibration signatures of different robotic frames and skeletons and are depicted in the papers [51-57]. Suitable mathematical expressions can be coined together to formulate rule based techniques [58-59] to address robot path planning problems and other engineering problems. Papers [6066] discuss about various vibration patterns in dynamic robotic structures with the help of smart intelligent techniques. Paper [67] discusses analysis of robot manipulator used for various tasks. Bacteria foraging method [68] is one of the promising artificial intelligence technique used for solving navigational path planning of mobile robot in cluttered environments. Differential evolution algorithm [69] has been used by the researchers to address many optimisation problems. Daykun-bip [70] AI technique is a smart computational method, used by researchers to address path planning of robots in unknown environments.

Using fuzzy inference techniques [71-74] researchers have solved many automated problems for various engineering applications. Several researchers have used fuzzy logic [75-78] for navigation control of robots. In papers [79-81] obstacles avoidance by robots has been achieved using fuzzy inference techniques. Papers [82-84] analyse robots movements using fuzzy logic techniques. Finite element methods have been discussed in papers [85-88] for addressing structural dynamics of various mechanical components in intelligent ways. Gait analysis of biped robot has been investigated by engineers in the paper [89]. Paper [90] discusses harmonic search AI technique for robot control.

Kinematic analyses of robots have been discussed in the papers [91-94]. Real time control of robot has been discussed in the paper [95]. Robot navigation can be addressed in unknown terrain using artificial intelligence techniques [96-97]. Simulated annealing [98] is mimicking of heat treatment processes and is used as a soft computing method for solving local minima problem during path planning of robots. Soft computing methods [99-100] have been used by engineers to address various problems related to control of robots movements. Paper [101] discusses hybrid AI Cuckoo-Neuro technique for robot path analysis in complex environments. Researchers have discussed about radial basis neural network [102] for control of robots in unknown scenarios. Hybrid method such as Simulated-Annealing-Neural technique has been discussed in the paper [103] for complex robot movements. Hybrid fuzzy immune [104] technique has been analysed by researchers for target seeking of robots in cluttered environments.

Mobile computing [105-106] can be used for addressing various intelligent network communications. In neural network [107-111] inputs are given to the neurons in input layers and output is obtained from neuron in output layer. Neural networks [112-116] have been used efficiently for robot navigation control of robot. Using Bat algorithm [117] researchers have tried to solve robot path planning problem. Neuro-fuzzy [118122] hybrid technique can be used efficiently for path planning of robots from start to goal point while avoiding obstacles. In this method neural algorithm has been hybridised with fuzzy inference methods to obtain neuro-fuzzy [123-125] hybrid technique. Various researchers have used neuro-fuzzy [126-128] techniques to control mobile robots. Paper [129] analyses Grey Wolf optimisation method for solving task management strategy being carried out by robot. Navigation of mobile robot using Cuckoo Search method has been discussed in the paper [130]. Papers [131-133] discusses about invasive weed optimisation technique for navigation and control of robot subjected to various conditions. Keeping in view the above findings a novel hybrid average genetic-neuro control technique has been developed in this paper to address navigation of mobile robots in cluttered unknown environments.

\section{Technical Explanation Genetic-Neural Controller Used for Robots Navigation}

Table 1: simulation and experimental path lengths and time taken during various exercises (hemisson robot [134]).

\begin{tabular}{|c|c|c|c|c|c|c|}
\hline Ex. No. & $\begin{array}{c}\text { Path Length (cm) } \\
\text { (Simulation) }\end{array}$ & $\begin{array}{c}\text { Path Length (cm) } \\
\text { (Experimental) }\end{array}$ & $\begin{array}{c}\text { Percentage De- } \\
\text { viation of Path }\end{array}$ & $\begin{array}{c}\text { Time Taken (Millisec- } \\
\text { onds) (Simulation) }\end{array}$ & $\begin{array}{c}\text { Time Taken (Millisec- } \\
\text { onds) (Experimental) }\end{array}$ & $\begin{array}{c}\text { Percentage Devi- } \\
\text { ation of Time }\end{array}$ \\
\hline 1 & 135 & 138 & 2.17 & 6750 & 6917 & 2.41 \\
\hline 2 & 302 & 306 & 1.3 & 15100 & 15338 & 1.55 \\
\hline 3 & 235 & 239 & 1.67 & 11750 & 11979 & 1.91 \\
\hline 4 & 274 & 281 & 2.49 & 13700 & 14085 & 2.73 \\
\hline 5 & 174 & 178 & 2.24 & 8700 & 8923 & 2.49 \\
\hline
\end{tabular}


In the current paper genetic and neural controllers are hybridised to get Genetic-Neural controller. The outputs from genetic and neural controllers are obtained separately and the average of them is taken as the final output from the hybrid controller. The inputs to the hybrid controller (Figure 1) are obstacle distances obtained from sensors mounted on front, left and right directions of the robots. The output from Genetic algorithm is steering angle-1 (SA-1) and the output from Neural network is steering angle-2 (SA-2). The Genetic algorithm uses several parents to produce offspring from the crossover and subsequently finds the best child to get SA-1 according to fitness function. The Neural network considered here consists of five layers. The input layer has three neurons. Three hidden layers have five, ten and three neurons. The output layer has one neuron representing SA-2. The Final Steering Angle (FSA) for robots is calculated by taking the average of SA-1 and SA-2. With the help of FSA robots negotiate with obstacles in the process of achieving targets during navigation. For carrying out the simulations and experiments exercises Khepera-II [134] and Hemisson [134] robots are used. Simulation and experimental results are shown in Tabular form (Tables 1-2) and pictorial form (Figure 2). The simulation and experimental results agree with each other and deviations between them are found to be within $2.8 \%$.

Table 2: Simulation and experimental path lengths and time taken during various exercises (khepera-ii robot [134]).

\begin{tabular}{|c|c|c|c|c|c|c|}
\hline Ex. No. & $\begin{array}{c}\text { Path Length (cm) } \\
\text { (Simulation) }\end{array}$ & $\begin{array}{c}\text { Path Length (cm) } \\
\text { (Experimental) }\end{array}$ & $\begin{array}{c}\text { Percentage De- } \\
\text { viation of Path }\end{array}$ & $\begin{array}{c}\text { Time Taken (Millisec- } \\
\text { onds) (Simulation) }\end{array}$ & $\begin{array}{c}\text { Time Taken (Millisec- } \\
\text { onds) (Experimental) }\end{array}$ & $\begin{array}{c}\text { Percentage Devi- } \\
\text { ation of Time }\end{array}$ \\
\hline 1 & 141 & 143 & 1.39 & 7050 & 7168 & 1.64 \\
\hline 2 & 288 & 291 & 1.03 & 14400 & 14586 & 1.27 \\
\hline 3 & 310 & 314 & 1.27 & 15500 & 15740 & 1.52 \\
\hline 4 & 185 & 189 & 2.11 & 9250 & 12782 & 2.36 \\
\hline 5 & 251 & 255 & 1.56 & 12550 & 27 & 1.81 \\
\hline
\end{tabular}

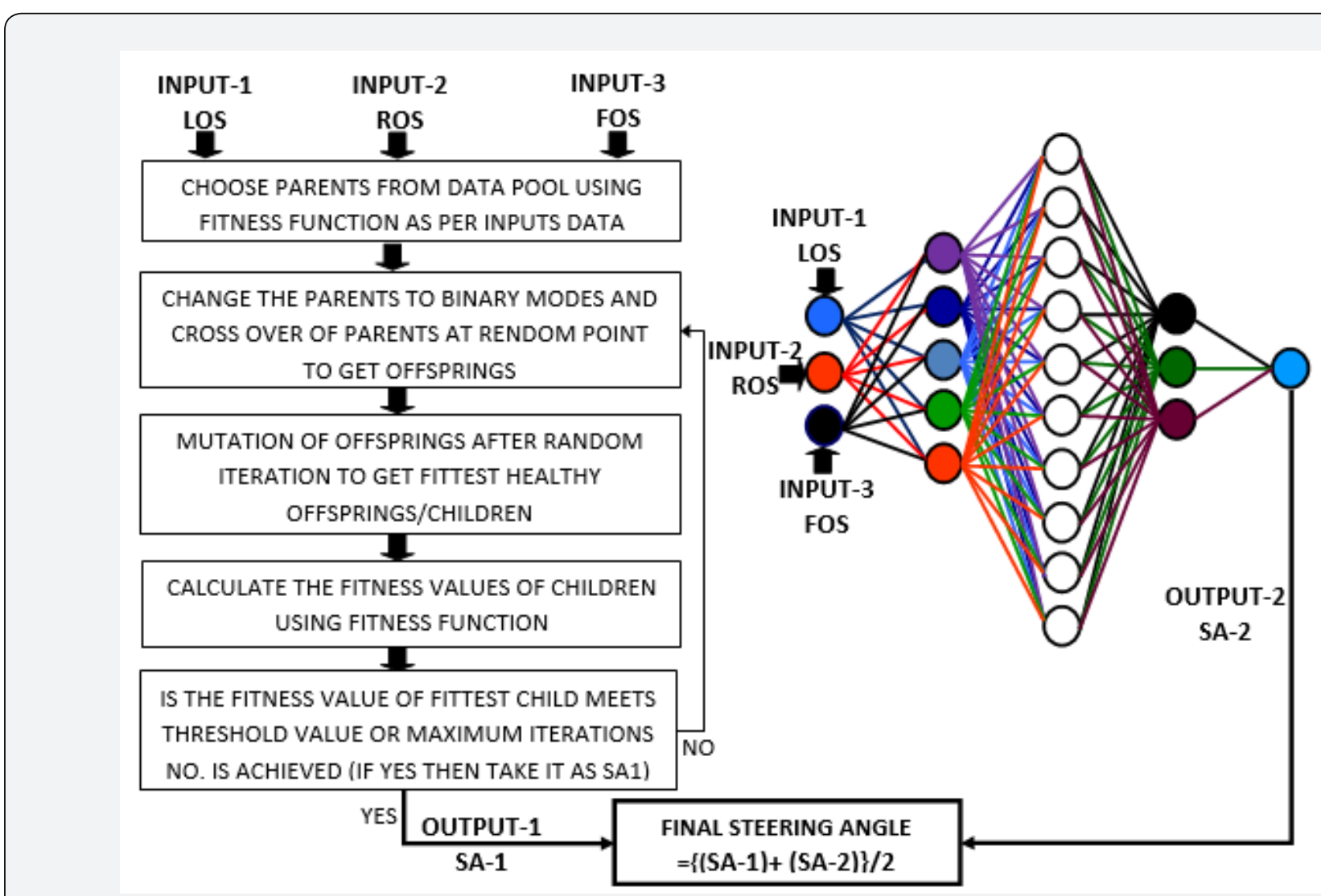

Figure 1: Architecture of Hybrid Genetic-Neural Control System. 


\section{Civil Engineering Research Journal}
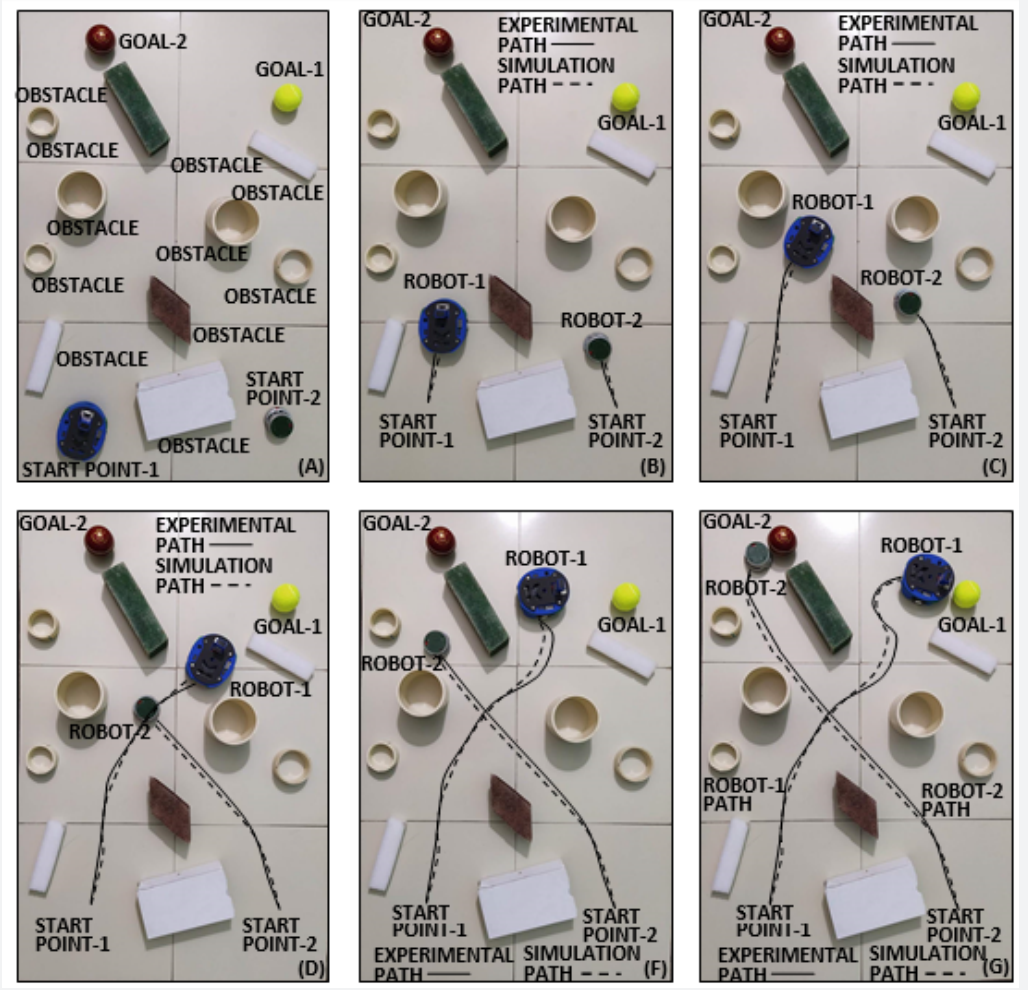

Figure 2: Simulation and Experimental Results of Hemisson \& Khepera-II [134] Robots from Starts to Goal Points.

\section{Conclusion}

In the current research Genetic-Neural hybrid control technique has been used to navigate mobile robots from start points to goal points. In the process steering angles SA-1 and SA-2 are obtained from Genetic and Neural parts of the hybrid algorithm. The FSA used for navigation is calculated by averaging SA-1 and SA-2 values. Using the Genetic-Neural hybrid control technique several exercises are conducted in simulation and experimental modes. The deviations between simulation and experimental results are found to be within $2.8 \%$. For carrying out the simulations and experiments exercises Khepera-II and Hemisson robots are used. From simulation and experimental results as depicted in tabular and pictorial forms show the efficiency of the proposed technique during navigation. GeneticNeural hybrid control technique can be used for solving other engineering problems as an AI technique where there is a need.

\section{References}

1. Reyes JGC, Schlam FFH, Garcia AR, Kriuchkova ER, Camarillo AM (2016) Design of a position control based on cuckoo search tuning for a cutter leaves robot. IEEE Latin America Transactions 14(5): 2085-2092.

2. Stojanovic V, Nedic N, Prsic D, Dubonjic L, Djordjevic V (2016) Application of cuckoo search algorithm to constrained control problem of a parallel robot platform. The International Journal of Advanced Manufacturing Technology 87(9-12): 2497-2507.

3. Kumar PB, Rawat H, Parhi DR (2018) Path planning of humanoids based on artificial potential field method in unknown environments. Expert Systems 36(2): e12360.
4. Mohanta JC, Parhi DR, Patel SK, Pradhan SK (2016) Real-Time Motion Planning of Multiple Mobile Robots Using Artificial Potential Field Method. Journal of Advance Computational Research 1(1): 1-16.

5. Deepak BB, Parhi DR (2012) PSO based path planner of an autonomous mobile robot. Open Computer Science 2(2): 152-168.

6. Panigrahi PK, Ghosh S, Parhi DR (2014) Comparison of GSA, SA and PSO based intelligent controllers for path planning of mobile robot in unknown environment. J Electr Comput Electron Commun Eng 8(10): $1523-1532$

7. Pandey A, Panwar VS, Hasan ME, Parhi DR (2020) V-REP-based navigation of automated wheeled robot between obstacles using PSOtuned feed forward neural network. Journal of Computational Design and Engineering 7(4): 427-434.

8. Huang HC (2013) Intelligent motion control for four-wheeled holonomic mobile robots using FPGA-based artificial immune system algorithm. Advances in Mechanical Engineering p: 1-11.

9. Deepak BB, Parhi DR (2016) Control of an automated mobile manipulator using artificial immune system. Journal of Experimental \& Theoretical Artificial Intelligence 28(1-2): 417-439.

10. Deepak BB, Parhi DR (2013) Intelligent adaptive immune-based motion planner of a mobile robot in cluttered environment. Intelligent Service Robotics 6(3): 155-162.

11. Deepak BB, Parhi DR, Kundu S (2012) Innate immune based path planner of an autonomous mobile robot. Procedia Engineering 38: 2663-2671.

12. Parhi DR, Deepak BB, Mohana J, Ruppa R, Nayak M (2012) Immunised navigational controller for mobile robot navigation. Soft computing techniques in vision science, Springer, Berlin, Heidelberg pp: 171-182. 


\section{Civil Engineering Research Journal}

13. Deepak BB, Jha AK, Parhi DR (2011) Path planning of an autonomous mobile robot using artificial immune system. Int J Comput Math Sci p: $1-6$.

14. Hidalgo-Paniagua A, Vega-Rodríguez MA, Ferruz J, Pavón N (2017) Solving the multi-objective path planning problem in mobile robotics with a firefly-based approach. Soft Computing 21(4): 949-964

15. Patle BK, Pandey A, Jagadeesh A, Parhi DR (2018) Path planning in uncertain environment by using firefly algorithm. Defence technology 14(6): 691-701.

16. Patle BK, Parhi DR, Jagadeesh A, Kashyap SK (2017) On firefly algorithm: optimization and application in mobile robot navigation World Journal of Engineering.

17. Timmis J, Andrews P, Hart E (2010) On artificial immune systems and swarm intelligence. Swarm Intelligence 4(4): 247-273.

18. Parhi DR, Pothal JK, Singh MK (2009) Navigation of multiple mobile robots using swarm intelligence. 2009 World Congress on Nature \& Biologically Inspired Computing (NaBIC) IEEE pp: 1145-1149.

19. Jena PK, Parhi DR (2015) A modified particle swarm optimization technique for crack detection in cantilever beams. Arabian Journal for Science and Engineering 40(11): 3263-3272.

20. Parhi DR, Sahu C, Kumar PB (2018) Navigation of multiple humanoid robots using hybrid adaptive swarm-adaptive ant colony optimisation technique. Computer Animation and Virtual Worlds e1802.

21. Kumar PB, Sahu C, Parhi DR (2018) Navigation of humanoids by a hybridized regression-adaptive particle swarm optimization approach. Archives of Control Sciences pp: 349-378.

22. Zhao S, Huang B, Liu F (2016) Localization of indoor mobile robot using minimum variance unbiased FIR filter. IEEE Transactions on Automation Science and Engineering 15(2): 410-419.

23. Diveev AI, Konstantinov SV (2018) Study of the practical convergence of evolutionary algorithms for the optimal program control of a wheeled robot. Journal of Computer and Systems Sciences International 57(4): 561-580.

24. Rawat H, Parhi DR, Priyadarshi BK, Pandey KK, Behera AK (2018) Analysis and Investigation of Mamdani Fuzzy for Control and Navigation of Mobile Robot and Exploration of Different AI Techniques Pertaining to Robot Navigation. Emerging trends in Engineering Science and Manufacturing IGIT, SARANG.

25. Dash AK, Parhi DR (2012) A vibration based inverse hybrid intelligent method for structural health monitoring, International Journal of Mechanical and Materials Engineering 6: 2.

26. Sahu C, Kumar PB, Parhi DR (2018) An intelligent path planning approach for humanoid robots using adaptive particle swarm optimization. International Journal on Artificial Intelligence Tools 27(05): 1850015

27. Kumar PB, Sethy M, Parhi DR (2019) An intelligent computer vision integrated regression based navigation approach for humanoids in a cluttered environment, Multimedia Tools and Applications 78(9): 11463-11486.

28. Parhi DR, Mohanty PK, A Study of various methodologies used for navigation of autonomous mobile robot. International Science Press: India,4,1 pp.19-26.

29. Pandey KK, Pol MS, Parhi DR (2014) Using an AI Technique Navigation and Path Planning for Mobile Robot on Webots Platform. IOSR Journal of Mechanical and Civil Engineering (IOSR-JMCE) p: 27-31.

30. Kumar PB, Sahu C, Parhi DR, Pandey KK, Chhotray A (2019) Static and dynamic path planning of humanoids using an advanced regression controller. Scientia Iranica 26(1): 375-393.

31. Kumar PB, Sahu C, Parhi DR (2020) Intelligent navigation of a selffabricated biped robot using a regression controller. Scientia Iranica 27(1): 262-272.

32. Kumar PB, Parhi DR (2020) Intelligent hybridization of regression technique with genetic algorithm for navigation of humanoids in complex environments. Robotica 38(4): 565-581.

33. Juang CF, Yeh YT (2017) Multi objective evolution of biped robot gaits using advanced continuous ant-colony optimized recurrent neural networks. IEEE transactions on cybernetics 48(6): 910-1922.

34. Kumar PB, Sahu C, Parhi DR (2018) A hybridized regression-adaptive ant colony optimization approach for navigation of humanoids in a cluttered environment. Applied Soft Computing, Elsevier 68: 565-585.

35. Sahu C, Parhi DR, Kumar PB (2018) An approach to optimize the path of humanoids using adaptive ant colony optimization. Journal of Bionic Engineering, Springer Singapore 623-635.

36. Juang CF, Yeh YT (2017) Multiobjective evolution of biped robot gaits using advanced continuous ant-colony optimized recurrent neural networks. IEEE transactions on cybernetics 48(6): 1910-1922.

37. Parhi DR, Chhotray A (2018) Development and analysis of DAYANI arc contour intelligent technique for navigation of two-wheeled mobile robot. Industrial Robot: An International Journal, Emerald Publishing Limited 45(5): 688-702.

38. Agarwalla DK, Parhi DR (2013) Effect of crack on modal parameters of a cantilever beam subjected to vibration. Procedia Engineering 51: 665-669.

39. Behera RK, Pandey A, Parhi DR (2014) Numerical and experimental verification of a method for prognosis of inclined edge crack in cantilever beam based on synthesis of mode shapes. Procedia Technology 14: 67-74.

40. Thatoi DN, Das HC, Parhi DR (2012) Review of techniques for fault diagnosis in damaged structure and engineering system. Advances in Mechanical Engineering 4: 327569.

41. Parhi DR, Behera AK (1997) Dynamic deflection of a cracked beam with moving mass. Proceedings of the Institution of Mechanical Engineers, Part C: Journal of Mechanical Engineering Science 211(1): 77-87.

42. Das HC, Parhi DR (2009) Application of neural network for fault diagnosis of cracked cantilever beam. 2009 World Congress on Nature \& Biologically Inspired Computing (NaBIC) IEEE pp: 1303-1308.

43. Jena PK, Thatoi DN, Nanda J, Parhi DR (2012) Effect of damage parameters on vibration signatures of a cantilever beam. Procedia engineering 38: 3318-3330

44. Parhi DR, Behera AK (1997) Dynamic deflection of a cracked shaft subjected to moving mass. Transactions of the Canadian Society for Mechanical Engineering 21(3): 295-316.

45. Jena PC, Parhi DR, Pohit G (2012) Faults detection of a single cracked beam by theoretical and experimental analysis using vibration signatures. IOSR Journal of Mechanical and Civil Engineering 4(3): 01 18.

46. Xue Y (2018) Mobile robot path planning with a non-dominated sorting genetic algorithm. Applied Sciences 8(11): p.2253.

47. Sahu S, Parhi DR (2014) Automatic design of fuzzy MF using Genetic Algorithm for fault detection in structural elements. 2014 Students Conference on Engineering and Systems, IEEE p: 1-5. 


\section{Civil Engineering Research Journal}

48. Rath AK, Parhi DR, Das HC, Kumar PB, Muni MK (2018) Path optimization for navigation of a humanoid robot using hybridized fuzzy-genetic algorithm. International Journal of Intelligent Unmanned Systems Volume 7 Issue 3.

49. Behera SK, Parhi DR, Das HC (2018) Application of genetic algorithm for crack diagnosis of a free-free aluminum beam with transverse crack subjected to axial and bending load. Journal of Mechanical Engineering and Sciences 12(3): 3825-3851.

50. Kumar PB, Parhi DR (2020) Navigational analysis of a humanoid using genetic algorithm with vision assistance. Multimedia Tools and Applications p: 1-20.

51. Parhi DR, Dash AK (2009) Analysis of methodologies applied for diagnosis of fault in vibrating structures. International Journal of Vehicle Noise and Vibration 5(4): 271-286.

52. Yadao AR, Singh RP, Parhi DR (2014) Influence of parameters of cracked rotor system on its vibration characteristics in viscous medium at finite region. In Applied mechanics and materials Trans Tech Publications Ltd 592: 2061-2065.

53. Parhi DR, Agarwalla DK (2012) Determination of Modified Natural Frequencies of Fractured Fixed-Fixed Beam by Numerical \& Experimental Method. IJAAIES 4(2): 95-101.

54. Parhi DR, Behera AK (1998) The study of virtual mass and damping effect on a rotating shaft in viscous medium. Journal-Institution of Engineers India Part MC Mechanical Engineering Division pp: 109-113.

55. Nanda J, Das S, Parhi DR (2014) Effect of Slenderness ratio on crack parameters of simply supported Shaft. Procedia materials science 6: 1428-1435.

56. Jena SP, Parhi DR, Subbaratnam B (2017) Parametric evaluation on the response of damaged simple supported structure under transit mass. Gas Turbine India Conference, American Society of Mechanica Engineers 58516: V002T05A003.

57. Parhi DR, Behera AK, Sahoo PK (1997) Dynamic Response of Beams with a Moving Mass. Journal-Aeronautical Society of India 49: 69-75.

58. Kumar SM, Kumar MD, Parhi DR, Prasad SM (2012) Intelligent controller for mobile robot based on heuristic rule base network Advanced Materials Research, Trans Tech Publications Ltd 403: 4777 4785.

59. Muni MK, Kumar PB, Parhi DR, Rath AK, Das HC (2020) Path Planning of a Humanoid Robot Using Rule-Based Technique. Advances in Mechanical Engineering Springer, Singapore, pp: 1547-1554.

60. Das HC, Parhi DR (2008) Modal analysis of vibrating structures impregnated with crack. International Journal of Applied Mechanics and Engineering 13(3): 639-652.

61. Parhi DR, Behera AK (1997) Vibration Characteristics of a Spinning Shaft in Viscous Liquid. JOURNAL-AERONAUTICAL SOCIETY OF INDIA 49: 174-179.

62. Kumar PB, Parhi DR (2017) Vibrational characteristics and stress analysis in a human femur bone. Materials Today: Proceedings 4(9) 10084-10087.

63. Jena SP, Parhi DR (2018) Dynamic response and analysis of cracked beam subjected to transit mass. International Journal of Dynamics and Control 6(3): 961-972.

64. Agarwalla DK, Parhi DR (2013) Diagnosis of Modal Characteristics of Aircraft Wing Model subjected to Irregularities. ijB 3: 1.

65. Jena SP, Parhi DR, Jena PC (2015) Dynamic Response of Damaged Cantilever Beam Subjected to Traversing Mass. International Journal For Technological Research In Engineering 2(7): 860-865.
66. Behera SK, Parhi DR, Das HC (2018) Numerical, experimental and fuzzy logic applications for investigation of crack location and crack depth estimation in a free-free aluminum beam. Vibrations in Physical Systems 29: 1-20.

67. Kumar PB, Verma NK, Parhi DR, Priyadarshi D (2019) Design and control of a 7 DOF redundant manipulator arm.Australian Journal of Mechanical Engineering, Taylor \& Francis p: 1-12.

68. Muni MK, Parhi DR, Kumar PB (2020) Improved Motion Planning of Humanoid Robots Using Bacterial Foraging Optimization, Robotica Cambridge University Press p: 1-14.

69. Sahu S, Kumar PB, Parhi DR (2019) Analysis of hybrid CSA-DEA method for fault detection of cracked structures.Journal of Theoretical and Applied Mechanics 57(2): 369-382.

70. Parhi DR, Kumar PB (2019) Smart navigation of humanoid robots using DAYKUN-BIP virtual target displacement and petri-net strategy, Robotica, Cambridge University Press 37(4): 626-640.

71. Wu L, Zhao R, Li Y, Chen YH (2020) Optimal Design of Adaptive Robust Control for the Delta Robot with Uncertainty: Fuzzy Set-Based Approach. Applied Sciences 10(10): 3472.

72. Parhi DR, Mohanta JC (2011) Navigational control of several mobile robotic agents using Petri-potential-fuzzy hybrid controller.Applied Soft Computing, Elsevier 11(4): 3546-3557.

73. Singh MK, Parhi DR, Bhowmik S, Kashyap SK (2008) Intelligent controller for mobile robot: Fuzzy logic approach. The $12^{\text {th }}$ International Conference of International Association for Computer Methods and Advances in Geomechanics (IACMAG) pp: 1-6.

74. Mohanty PK, Parhi DR (2014) Navigation of autonomous mobile robot using adaptive network based fuzzy inference system. Journal of Mechanical Science and Technology, Korean Society of Mechanical Engineers, 28,7, 2861-2868.

75. Parhi DR, Choudhury S (2011) Smart crack detection of a cracked cantilever beam using fuzzy logic technology with hybrid membership functions. Journal of Engineering and Technology research, Academic Journals 3(8): 270-278.

76. Parhi DR, Singh MK (2008) Intelligent fuzzy interface technique for the control of an autonomous mobile robot. Proceedings of the Institution of Mechanical Engineers, Part C: Journal of Mechanical Engineering Science, SAGE Publications, 222(11): 2281-2292.

77. Rath AK, Parhi DR, Das HC, Muni MK, Kumar PB (2018) Analysis and use of fuzzy intelligent technique for navigation of humanoid robot in obstacle prone zone. Defence technology, Elsevier 14(6): 677-682.

78. Pandey A, Parhi DR (2014) MATLAB simulation for mobile robot navigation with hurdles in cluttered environment using minimum rule based fuzzy logic controller, Procedia technology 14(1): 28-34.

79. Mohanty PK, Parhi DR, Jha AK, Pandey A (2013) Path planning of an autonomous mobile robot using adaptive network based fuzzy controller,2013 3rd IEEE International Advance Computing Conference (IACC), IEEE pp: 651-656.

80. Mohanty S, Parhi DR, Das SS (2018) Control strategy of a real mobile robot using singleton takagi sugeno fuzzy inference methodology within the frame work of artificial intelligence techniques. Emerging Trends in Engineering, Science and Manufacturing (ETESM-2018), IGIT Sarang, India 576.

81. Panigrahi PK, Ghosh S, Parhi DR (2014) A Comparison of Mamdani and Sugeno Based Fuzzy Controller for Mobile Robot to Avoid Static Obstacles. 5th International Elsevier Conference Electronics and Computer Science (IEMCON) pp: 226-231. 


\section{Civil Engineering Research Journal}

82. Mohanty S, Parhi DR, Das SS, Pradhan S (2018) Path Control Using Hybrid Mamdani Sugeno Fuzzy Controller for a Real Mobile Robot. International Journal of Applied Artificial Intelligence in Engineering System pp: 1-21.

83. Mohanty S, Parhi DR, Das SS, Pradhan SK, Chhotray A (2018) Experimental Investigation on Traversed Path of Moving Robot Using Rule-Based-Fuzzy Integrated Method In a Densely Populated Environment. International Journal of Artificial Intelligence and Computational Research (IJAICR) 10(1): 33-49.

84. Deepak BB, Parhi DR (2019) New strategy for mobile robot navigation using fuzzy logic. Information Systems Design and Intelligent Applications Springer, Singapore p: 1-8.

85. Khan IA, Parhi DR (2013) Finite element analysis of double cracked beam and its experimental validation. Procedia Engineering Elsevier 51: 703-708.

86. Parhi DR, Dash AK (2011) Application of neural network and finite element for condition monitoring of structures. Proceedings of the Institution of Mechanical Engineers, Part C: Journal of Mechanical Engineering Science 225(6): 1329-1339.

87. Jena PC, Parhi DR, Pohit G (2014) Theoretical, Numerical (FEM) and Experimental Analysis of composite cracked beams of different boundary conditions using vibration mode shape curvatures International Journal of Engineering and technology 6(2): 509-518.

88. Parhi DR, Muni MK, Sahu C (2012) Diagnosis of Cracks in Structures Using FEA Analysis. International Science Press: India (IJAAIES) 4(1): 27-42.

89. Kashyap AK, Pandey A, Chhotray A, Parhi DR (2020) Controlled Gait Planning of Humanoid Robot NAO Based on 3D-LIPM Model. Available at SSRN 3552498.

90. Kundu S, Parhi DR (2016) Navigation of underwater robot based on dynamically adaptive harmony search algorithm. Memetic Computing 8(2): 125-146.

91. Parhi DR, Deepak BB (2011) Kinematic model of three wheeled mobile robot. Journal of Mechanical Engineering Research 3(9): 307-318.

92. Parhi DR, Behera AK, Pandey KK, Chhotray A, Kumar PB Study and Analysis of Hybrid Genetic-Adaptive-Rulebase Method for Path Control of Multiple Wheeled Mobile Robotic Agent. International Journal of Artificial Intelligence and Computational Research (IJAICR) 10(1): 1732.

93. Deepak BB, Parhi DR (2011) Kinematic analysis of wheeled mobile robot. Automation \& Systems Engineering 5(2): 96-111.

94. Parhi DR, Kumar PB, Behera AK, Pandey KK, Chhotray A (2018) Contour Analysis of a Dynamic Robot In a Cluttered Environment using GeneticCuckoo Search Method. International Journal of Artificial Intelligence and Computational Research (IJAICR) 10(1): 51-66.

95. Patle BK, Parhi DR, Jagadeesh A, Sahu OP (2017) Real Time Navigation Approach for Mobile Robot. JCP 12(2): 135-142.

96. Patle BK, Pandey A, Parhi DR, Jagadeesh A (2019) A review: On path planning strategies for navigation of mobile robot. Defence Technology 15(4): 582-606

97. Parhi DR, Singh MK (2009) Navigational strategies of mobile robots: a review. International Journal of Automation and Control 3(2-3): 114134

98. Kashyap AK, Parhi DR, Kumar S (2020) Dynamic stabilization of NAO humanoid robot based on whole-body control with simulated annealing. International Journal of Humanoid Robotics 17(3): 2050014.

99. Parhi DR, Pradhan SK, Panda AK, Behera RK (2009) The stable and precise motion control for multiple mobile robots. Applied Soft Computing 9(2): 477-487.

100. Kumar PB, Muni MK, Parhi DR (2020) Navigational analysis of multiple humanoids using a hybrid regression-fuzzy logic control approach in complex terrains. Applied Soft Computing 89: 106088.

101. Das SS, Parhi DR, Mohanty S, Pradhan SK, Chhotray A (2018) Analysis of Path Architecture of Mobile Robotic Platform with the Help of Cuckoo-Neuro Search Algorithm. International Journal of Artificial Intelligence and Computational Research (IJAICR) 10(1): 67-83.

102. Mohanty S, Parhi DR, Das SS, Pradhan SK, Pandey KK (2018) Motion and Track Analysis of A Several Wheeled Robot using Hybrid Genetic-Radial-Basis-Neural AI Technique Subjected To Different Environmental Conditions. International Journal of Artificial Intelligence and Computational Research (IJAICR) 10(1): 85-101.

103. Das SS, Parhi DR, Mohanty S, Kumar PB, Pradhan SK (2018) Path and Movement Study of a Biped Robot using Simulated-Annealing-Neural Method in the Presence of Target and Obstacles. International Journal of Artificial Intelligence and Computational Research (IJAICR) 10(1): 103-119.

104. Mohanty S, Parhi DR, Das SS, Pradhan SK, Pandey KK (2018) Target Finding and Obstacle Avoidance Behaviour Study of A Humanoid Robot with the Help of Embedded Hybrid Fuzzy-Immune Method. International Journal of Artificial Intelligence and Computational Research (IJAICR) 10(1): 121-137.

105. Elappila M, Chinara S, Parhi DR (2018) Survivable path routing in WSN for IoT applications. Pervasive and Mobile Computing 43: 4963.

106. Elappila M, Chinara S, Parhi DR (2020) Survivability Aware Channel Allocation in WSN for IoT applications. Pervasive and Mobile Computing. 61: 101107.

107. Sharkawy AN, Koustoumpardis PN, Aspragathos N (2020) Humanrobot collisions detection for safe human-robot interaction using one multi-input-output neural network. Soft Computing 24(9): 6687-6719.

108. Parhi DR, Singh MK (2009) Real-time navigational control of mobile robots using an artificial neural network. Proceedings of the Institution of Mechanical Engineers, Part C: Journal of Mechanical Engineering Science 223(7): 1713-1725.

109. Pham DT, Parhi DR (2003) Navigation of multiple mobile robots using a neural network and a Petri Net model. Robotica 21(1): 79-93.

110. Mohanty JR, Verma BB, Parhi DR, Ray PK (2009) Application of artificial neural network for predicting fatigue crack propagation life of aluminum alloys. Association of Computational Materials Science and Surface Engineering, 1(3): 133-138.

111. Das SS, Parhi DR, Mohanty S, Pradhan SK, Pandey KK (2018) Behavioural Study of Dynamic Robot During Path Planning in an Environment using Neural-Rule-Based Artificial Intelligence Technique. International Journal of Artificial Intelligence and Computational Research (IJAICR) 10(1): 1-16.

112. Rath AK, Das HC, Parhi DR, Kumar PB (2018) Application of artificial neural network for control and navigation of humanoid robot. Journal of Mechanical Engineering and Sciences 12(2): 3529-3538.

113. Pandey KK, Parhi DR (2020) Trajectory planning and the target search by the mobile robot in an environment using a BehaviorBased neural network approach. Robotica pp.1627-1641.

114. Chhotray A, Parhi DR (2019) Navigational control analysis of twowheeled self-balancing robot in an unknown terrain using backpropagation neural network integrated modified DAYANI approach. Robotica 37(8): 1346-1362. 


\section{Civil Engineering Research Journal}

115. Jena PC, Parhi DR, Pohit G (2019) Dynamic Investigation of FRP Cracked Beam Using Neural Network Technique. Journal of Vibration Engineering \& Technologies 7(6): 647-661.

116. Nanda J, Das LD, Choudhury S, Parhi DR (2020) Revelence of Multiple Breathing Cracks on Fixed Shaft Using ANFIS and ANN. Innovative Product Design and Intelligent Manufacturing Systems Springer, Singapore pp: 599-618.

117. Ghosh S, Panigrahi PK, Parhi DR (2017) Analysis of FPA and BA meta-heuristic controllers for optimal path planning of mobile robot in cluttered environment. IET Science, Measurement \& Technology 11(7): 817-828

118. Lazreg M, Benamrane N (2019) Intelligent System for Robotic Navigation Using ANFIS and ACOr. Applied Artificial Intelligence 33(5): 399-419.

119. Mohanty PK, Parhi DR (2015) A new hybrid optimization algorithm for multiple mobile robot's navigation based on the CS-ANFIS approach. Memetic Computing 7(4): 255-273.

120. Pandey A, Parhi DR (2016) Multiple mobile robots navigation and obstacle avoidance using minimum rule based ANFIS network controller in the cluttered environment. International Journal of Advanced Robotics and Automation 1(1): 1-11.

121. Singh MK, Parhi DR, Pothal JK (2009) ANFIS approach for navigation of mobile robots. In 2009 International Conference on Advances in Recent Technologies in Communication and Computing IEEE pp: 727-731.

122. Pandey A, Kumar S, Pandey KK, Parhi DR (2016) Mobile robot navigation in unknown static environments using ANFIS controller. Perspectives in Science 8: 421-423.

123. Mohanty PK, Parhi DR (2014) Path planning strategy for mobile robot navigation using MANFIS controller. In Proceedings of the International Conference on Frontiers of Intelligent Computing: Theory and Applications (FICTA) 2013 Springer, Cham, pp: 353-361

124. Kundu S, Parhi DR, Deepak BB (2012) Fuzzy-neuro based navigationa strategy for mobile robot. International Journal of Scientific \& Engineering Research 3(6): 1-6.
125. Parhi DR, Mohanty PK (2016) IWO-based adaptive neuro-fuzzy controller for mobile robot navigation in cluttered environments. The International Journal of Advanced Manufacturing Technology 83(9-12): 1607-1625.

126. Yadao AR, Parhi DR (2017) Dynamic Analysis of Fixed-Fixed Type Cracked Rotor in Viscous Medium. Journal of Vibration Engineering \& Technologies 5(6): 535-546.

127. Pandey A, Kashyap AK, Parhi DR, Patle BK (2019) Autonomous mobile robot navigation between static and dynamic obstacles using multiple ANFIS architecture. World Journal of Engineering 16(2): 275-286.

128. Pradhan SK, Parhi DR, Panda AK (2006) Navigation of multiple mobile robots using rule-based neuro-fuzzy technique. International Journal of Computational Intelligence 3(2): 142-152.

129. Li J, Yang F (2020) Task assignment strategy for multi-robot based on improved Grey Wolf Optimizer. Journal of Ambient Intelligence and Humanized Computing 11(12): 6319-6335.

130. Mohanty PK, Parhi DR (2013) Cuckoo search algorithm for the mobile robot navigation. International Conference on Swarm, Evolutionary, and Memetic Computing, Springer, Cham pp: 527-536.

131. Mohanty PK, Parhi DR (2014) A new efficient optimal path planner for mobile robot based on Invasive Weed Optimization algorithm. Frontiers of Mechanical Engineering 9(4): 317-330.

132. Mandava RK, Vundavilli PR (2018) Implementation of modified chaotic invasive weed optimization algorithm for optimizing the PID controller of the biped robot. Sādhanā 43(5): 66

133. Le PN, Kang HJ (2020) A Robotic Calibration Method Using a ModelBased Identification Technique and an Invasive Weed Optimization Neural Network Compensator. Applied Sciences 10(20): 7320.

134. https://www.k-team.com/

\section{Your next submission with Juniper Publishers} will reach you the below assets

- Quality Editorial service

- Swift Peer Review

- Reprints availability

- E-prints Service

- Manuscript Podcast for convenient understanding

- Global attainment for your research

- Manuscript accessibility in different formats

( Pdf, E-pub, Full Text, Audio)

- Unceasing customer service

Track the below URL for one-step submission https://juniperpublishers.com/online-submission.php 